\title{
INTERNATIONAL MASTER BIM MANAGER EM LÍNGUA PORTUGUESA - EXPERIÊNCIA COLABORATIVA EM ENSINO À DISTÂNCIA
}

\author{
José Lino $^{(1)}$, Gustavo Ferreiro ${ }^{(1)}$, Antonio Tort ${ }^{(2)}$, Daniel Félix ${ }^{(1)}$ \\ (1) NossoBIM - Estados Unidos da América, Portugal, Brasil \\ (2) BIM Skills - Espanha
}

\begin{abstract}
Resumo
A evolução da maturidade em BIM, de pessoas e organizações, está intimamente relacionada com as oportunidades de acesso a ações de educação e formação profissional nesta área.

No primeiro aspeto, ao qual normalmente se dedicam as Universidades, a natural inércia inerente a alterar os processos educativos tradicionais para integrarem estes conceitos e metodologias mais modernas, tem-se revelado um retardador desta adoção de BIM. Por outro lado, a maioria das ofertas de formação profissional existentes, muito centradas nas habilidades e no domínio de ferramentas, raramente incluem a visão integrada de alto nível que nos dá a justificação e o posicionamento estratégico das tarefas apreendidas.

Neste cenário, os autores convergiram para criar uma oferta formativa em língua portuguesa para profissionais da indústria da Arquitetura, Engenharia, Construção e Operação (AECO). A metodologia de ensino é baseada no ensino online, advogando a filosofia do open-BIM, adotando múltiplas plataformas e múltiplas ferramentas, estimulando a comunicação e o trabalho em equipa entre grupos de trabalho a quem são propostos desafios ao longo do curso e que imitam as situações reais com que o profissional se tem que deparar. O ambiente digital e a necessidade de colaborar à distância, estimulam a interação entre alunos e professores garantindo um alcance alargado a profissionais espalhados por vários países e continentes.

O International Master BIM Manager em língua portuguesa atinge na sua $5^{\text {a }}$ edição um total de mais de 700 profissionais provenientes de vários países, tendo-se revelando líder de mercado em língua Portuguesa na oferta de ensino online de BIM, de alto padrão. São descritas as dificuldades que surgiram ao longo de todo desenvolvimento e operação, bem como as principais vantagens elencadas pelos alunos.
\end{abstract}

\section{Introdução}

A par do progresso e da evolução inexorável dos métodos e processos inerentes à indústria AECO, alguma inércia e tradicionalismo teimam em atrasar o aumento da maturidade em 
Building Information Modelling (BIM), nesta que é uma das mais importantes indústrias para o desenvolvimento das economias, do Produto Interno Bruto e das taxas de emprego dos países. Associado a uma, cada vez maior, adesão, por parte dos mercados e dos governos, ao BIM, muitos partindo já para mandatos BIM obrigatórios, a falta de conhecimento e de competências tem sido identificada numa correlação direta com o aumento desta maturidade. Assim há que proceder a um investimento pessoal e coletivo quer em formação profissional quer educação superior em pessoas e organizações, contribuindo para o aumento dos conhecimentos, das habilidades, logo das competências em BIM, necessárias para essa mudança.

Começa a percecionar-se que os governos e organizações percebem a importância dum tipo de formação global, abrangente, mas simultaneamente prático e profissional que habilite as pessoas a fazerem diferente, e consequentemente melhor. Com o enquadramento global aqui mencionado, com uma demanda exponencialmente crescente de profissionais com conhecimentos concretos em BIM, o perfil de BIM Manager torna-se vital para a coordenação e correta implementação de toda a estrutura organizativa.

Foi neste panorama e com esta necessidade que, em 2014, e na sequência de uma experiência pioneira em língua espanhola, virada para a formação premium e alongada de BIM Managers, os autores resolveram criar uma experiência idêntica em Português Internacional, fundando a empresa NossoBIM, responsável pela componente pedagógica e académica, pelos conteúdos e representando um naipe alargado de professores. Para o desenvolvimento desta experiência foi criado um consórcio em parceria com o instituto Zigurat que ficou encarregue das componentes de Marketing e Comerciais.

Nasceu assim o International Master BIM Manager em Língua Portuguesa que vai iniciar a sua $6^{a}$ edição, contando já com cerca de 700 alunos e sendo, entre outros, acreditado como base letiva para um curso de especialização lato sensu pelo Ministério de Educação Brasileiro.

\section{Criação, Metodologia e Perfis BIM}

\subsection{Criação}

A génese deste curso parte de uma ideia original dos Arquitetos Gustavo Ferreiro e António Tort, que fruto da sua experiência de aplicação prática em BIM, perceberam a necessidade de compilar este produto e desenvolver uma metodologia pedagógica que lhe estivesse inerente. Surgiu assim o International BIM Master em língua espanhola. Percebendo a necessidade de expandir o produto para outros mercados e outras línguas, em fevereiro de 2014 convidaram José Carlos Lino para assumir a direção académica e conjuntamente com Daniel Félix na Coordenação Técnica iniciaram a criação dos conteúdos para a segunda língua do International Master BIM Manager, neste caso, o Português internacional. A ideia de fazer em Português Internacional, sabendo as diferenças que existem nos diversos países que falam o Português, sejam elas ortográficas, gramaticais ou fonéticas, serviu como plataforma de união, ultrapassando fronteiras e criando pontes que atravessam o Atlântico e são capazes de unir os falantes de Português dispostos pelos quatro cantos do Mundo. Tal só foi possível com a inteligência cooperativa de todos os que resolveram aderir a esta ideia, professores e alunos, porventura derrubando barreiras de purismo que apenas impedem o desenvolvimento global. O curso foi criado para uma duração letiva de 600 horas, inicialmente dispostas ao longo de 18 meses e a partir da $3^{a}$ edição reduzida para 12 meses. Imagina-se uma carga horária semanal de 12 a 14 horas por aluno que envolve o estudo das ferramentas, visionamento de vídeos, leitura 
de material escrito e participação em trabalhos. O curso atualmente encontra-se na sua $5^{\mathrm{a}}$ ediç̧ão, tendo tido um número variável de alunos de cerca de 90 a 150 por edição e perfazendo um total de mais de 700 alunos participantes.

A maioria dos alunos são Arquitetos e Engenheiros mas, cada vez mais, se têm encontrado outros profissionais ligados à indústria como preparadores, desenhadores, medidores, topógrafos e também alguns ligados às áreas de gestão e administração.

Os profissionais têm componentes de aprendizagem individual, mas também participam em trabalhos de grupo. Para a constituição desses grupos a equipa de coordenação técnica e de tutoria aos alunos, procura criar grupos heterogéneos que permitam, em contexto de realização dos trabalhos apresentar valências complementares e partilhar experiências com distintos perfis. Essa heterogeneidade de conhecimentos e experiências de base é um dos fatores mais complexos de gerir, mas ao mesmo tempo mais enriquecedores para o aluno pois permite-lhe ter uma experiência alargada e uma simulação do que é uma experiência profissional real.

\subsection{Metodologia pedagógica e académica}

A metodologia de ensino é baseada no ensino online, advogando a filosofia do open-BIM, adotando múltiplas plataformas e múltiplas ferramentas, estimulando a comunicação e o trabalho em equipa entre grupos de trabalho a quem são propostos desafios ao longo do curso e que imitam as situações com que o profissional se tem que deparar. Para que isto seja possível, é necessário dotar o curso das plataformas colaborativas, da plataforma de ensino Learning Management System (LMS) e da gestão dos conteúdos, que lhe proporciona uma experiência de aprendizagem completa, dinâmica e online.

Assim, o aluno tem contacto com a plataforma de ensino (Moodle/Canvas) onde pode consultar os conteúdos e colocar dúvidas aos professores ou tutores, usa o Google Drive e ferramentas de comunicação online para reunir e trabalhar à distância, usa o Podio como plataforma colaborativa de gestão de equipas e de projeto e também servidores BIM para poder gerir todos os modelos e objetos.

Além de tudo isto, muitas Software houses aderiram a esta iniciativa proporcionando licenças académicas aos alunos nas diversas áreas (Aecosim - Bentley, AllPlan - Nemetcheck; Archicad - Graphisoft; Revit- Autodesk; Vico; Synchro; Navisworks; Archibus; Solibri; Cype; Tekla; DDS-CAD, entre outros).

Um dos conceitos de base deste curso nasceu das múltipla ferramentas e plataformas. Por exemplo na área da modelação BIM, os alunos começam por escolher no mínimo 2 das 4 plataformas de modelação possíveis de adotar (Aecosim, AllPlan, Archicad ou Revit).

Ao longo do curso vai sendo disponibilizado aos alunos, material didático diversificado, em formato de vídeo (mais de 80 h), PDFs com conteúdos escritos (mais de 5000 pags A4), são feitos webinars de aprofundamento, esclarecimento e de divulgação (mais de 10) e também são realizados eventos de divulgação ( 2 a 4 por ano) que permitem aos alunos daquela região, o contacto com o corpo docente e com os coordenadores e tutores.

Para que o trabalho colaborativo à distância tenha identificação com a metodologia BIM e com as melhores práticas internacionais em equipas e mercados, conforme já se mencionou, houve a necessidade de implementar servidores BIM para partilha de modelos federados, usando comunicação e troca de informação alocada ao modelo (Revit Server; Graphisoft BIM Cloud; Google Drive; Projectwise; BIM Collab, entre outros). 


\subsection{Perfis BIM}

Uma das mais valias, comumente elogiada, na metodologia pedagógica deste curso, e inclusivamente servindo de forte inspiração para os trabalhos do grupo de educação da comissão de normalização europeia CEN TC442, são os perfis de competências BIM (ver Figura 1).

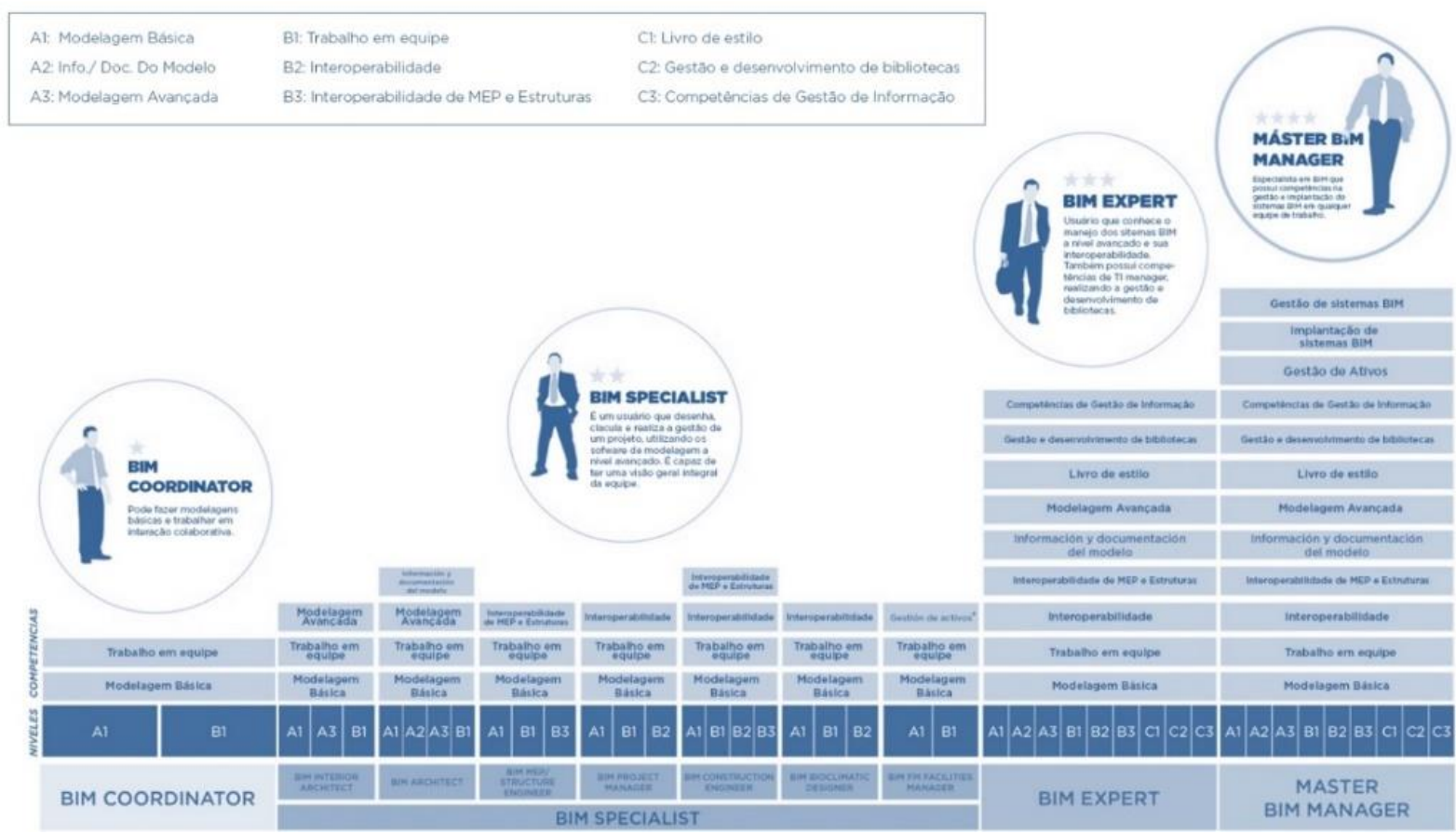

Figura 1: Perfis BIM.

Partindo progressivamente de conhecimentos e habilidades mais simples (nível 1), até às mais complexas (nível 3), misturando capacidades de modelação (A), de trabalho colaborativo (B) e de gestão (C) assim se vão criando os perfis BIM na evolução da formação, nomeadamente:

- $\quad$ BIM Coordinator: A1, B1

- BIM Specialist: A1, A2 e A3; B1, B2 e B3

- $\quad$ BIM Expert: A1, A2 e A3; B1, B2 e B3; C1, C2 e C3.

- BIM Manager: acresce a Gestão de Projetos, de Implementações e de Ativos

\section{Programa}

O conteúdo programático do curso, de um modo simplificado, está dividido em Blocos, Módulos, Temas e Partes. Para organização da matéria e para melhor apreensão pelo aluno, as temáticas são agrupadas por interesses comuns, sendo muito variável o número de subdivisões que um dado Bloco ou Tema podem conter, desde a aula isolada a várias dezenas de partes explicando aspetos específicos daquela matéria.

Como já foi dito, o desenvolvimento da matéria vai acompanhando a progressão do aluno ao longo dos perfis BIM até atingir com o último módulo o estatuto de BIM Manager. Não são 
colocados quaisquer pré-requisitos ao aluno em termos de conhecimento BIM, partindo do princípio de que todos os participantes estão de algum modo relacionados profissionalmente ou academicamente com o setor AECO. Assim, a progressão no curso permite ao aluno o estudo da metodologia BIM desde os princípios mais básicos até ao momento de entendimento dos conceitos e princípios de execução e implementação BIM, bem como a aprendizagem de ferramentas com conteúdos didáticos que começam com a própria instalação e explicação elementar da generalidade dos comandos, até ao domínio das mesmas a um nível avançado. Nas primeiras edições o curso estava dividido em 6 módulos mas com as alterações académicas que foram sendo feitas, compilaram-se o M5, M6a e M6b num módulo só. Na sua versão mais recente, o programa do International Master BIM Manager em língua Portuguesa, engloba 5 Módulos principais:

MÓDULO 1 - BIM SPECIALIST (Bloco 1. Competências de coordenação; Bloco 2. Competências de projeto; Bloco 3. Competências de engenharia)

Neste primeiro módulo, sendo o primeiro contacto de muitos alunos com a metodologia BIM, estes adquirem competências que lhes permitem atingir os dois perfis BIM iniciais: o BIM Coordinator e o BIM Specialist. No primeiro perfil, que é alcançado logo nos dois primeiros meses, os alunos adquirem competências de modelação básica e noções essenciais de trabalho colaborativo, sendo por isso capazes de se enquadrarem em trabalhos de equipa, bem como de assumirem tarefas de coordenação. Prosseguindo com os estudos e tendo em conta as competências adquiridas, os alunos iniciam o primeiro trabalho prático colaborativo, detalhado mais à frente, iniciando a aplicação dos conhecimentos do perfil BIM Coordinator. Simultaneamente, continuam a estudar conteúdo e a aprender a manipular ferramentas com aumento gradual de complexidade. Ainda neste módulo têm o primeiro contato com as várias dimensões do BIM, 4D, 5D e 7D, bem como aprendem conceitos de interoperabilidade.

Este módulo é por isso um elemento fundamental para a consolidação dos conhecimentos e conceitos essenciais da metodologia BIM, nomeadamente o uso de várias ferramentas (múltiplas plataformas), trabalho colaborativo e interoperabilidade. Para além disso, os alunos após atingirem o perfil BIM coordinator complementam o estudo individual com o desenvolvimento de trabalho prático em equipa, mantendo esta simultaneidade de estudo e aplicação prática até ao final do curso.

MÓDULO 2 - BIM EXPERT (Bloco 1. Competências em gestão de informação; Bloco 2. Competências no desenvolvimento de objetos; Bloco 3. Competências em organização)

O segundo módulo consolida conceitos de interoperabilidade, sendo os alunos desafiados a colocarem em prática conceitos de gestão de informação com conteúdo dedicado a verificação de colisões e compatibilização de diversos modelos, nas suas diversas disciplinas. São ainda abordadas questões de organização de equipa e projeto, nomeadamente com conteúdo e aplicação prática do mesmo para o desenvolvimento de um livro de estilo, e por fim com a introdução ao desenvolvimento de objetos BIM e bibliotecas. No final deste módulo os alunos atingem o perfil de BIM Expert.

MÓDULO 3 - BIM MANAGEMENT (Bloco 1. AEC na era digital; Bloco 2. BEP. BIM Execution Plan; Bloco 3. IDM, protocolos, sistemas de classificação e normas da organização; Bloco 4. Prática colaborativa. BIM Level 3; Bloco 5. Controlo de qualidade da modelação; Bloco 6. Estratégias de gestão BIM) 
Neste módulo focamo-nos na aplicação concreta do conceito e metodologia BIM a um projeto discutindo as diversas estratégias de implementação dos diversos usos BIM ao longo do ciclo de vida de um empreendimento de construção bem como a interoperabilidade e as trocas que tal acarreta entre as diversas partes interessadas. O perfil do BIM Manager e as suas competências são explicitadas com vista a compreender o importante papel para o sucesso desta implementação. Um destaque central é naturalmente dado à construção do BIM Execution Plan - Plano de execução BIM e à sua materialização sendo um dos importantes trabalhos de grupo deste módulo.

MÓDULO 4 - BIM IMPLEMENTATION (Bloco 1. O papel e o mercado do BIM Manager; Bloco 2. BIM Implementation Plan; Bloco 3. Estratégias de Implementação; Bloco 4. Análise da Organização; Bloco 5. Implementando; Bloco 6. Construindo a equipa)

Neste módulo discutem-se os desafios da mudança nas organizações bem como as suas estruturas e a implicação que tal traz na implementação sustentada do BIM. O papel do BIM Manager volta a ser realçado e elevado até à função do gestor de topo que proporciona à direção o apoio às decisões e estratégias que estejam em consonância com a missão, visão e objetivos da organização.

MÓDULO 5 - APLICAÇÕES ESPECÍFICAS - EDIFÍCIOS (Bloco 1. Programação Visual; Bloco 2. Reabilitação Sustentável; Bloco 3. Facility Management (FM); Bloco 4. Objetos para a Indústria)

Neste último módulo dá-se uma diferenciação entre a versão edifícios e de infraestruturas. Aos alunos de edifícios é solicitada a aplicação a um caso de análises energética e dado a escolher a hipótese de fabricação digital ou FM.

MÓDULO 5 - APLICAÇÕES ESPECÍFICAS - INFRAESTRUTURAS (Bloco 1. Programação Visual; Bloco 2. Levantamento do existente; Bloco 3. Vias de Comunicação; Bloco 4. Indústria de Estruturas Metálicas; Bloco 5. Bridge Information Modelling)

Aos alunos de infraestruturas e dada a multiplicidade de hipóteses de infraestruturas existentes (Rodovias, Ferrovias, Túneis, Pontes, Infraestruturas hidráulicas lineares, Infraestruturas hidráulicas compostas por órgãos, Aeroportos, Portos, etc, é pedida uma aplicação específica que acaba por resumir e conglomerar todo o conhecimento e habilidades adquiridas desde o início.

\section{Equipa de apoio ao aluno}

\subsection{Professores}

Um dos grandes diferenciais apontado a este curso tem sido a composição do seu corpo docente e de tutoria. Sendo um curso destinado à maioria da população profissional, logo procurou alinhar-se com a média das expectativas e capacidades dos alunos candidatos. Pelo contrário, para docentes, foram identificados professores de excecional qualidade e desenvoltura nas suas áreas. Os quatro perfis de professores são os professores referência nacional e internacional, que fazem parte concomitante das estratégias nacionais e que são citados enquanto pioneiros na implementação BIM, os professores conceituais, académicos, com capacidade de explicar não apenas as ideias mas também os porquês subjacentes, os professores profissionais que 
aplicam BIM nas suas atividades do dia a dia e podem falar delas na primeira pessoa e com exemplos práticos de aplicação e, por último, os professores ferramentais, que utilizam as ferramentas no seu trabalho, apesar de normalmente não estarem vinculados às marcas nem às Software houses. Os professores não só são responsáveis pela criação de conteúdo, como da resposta aos fóruns de perguntas lançadas pelos alunos, pelas avaliações dos trabalhos e pelos webinars e outras ações de divulgação e de marketing. A NossoBIM apenas representa o professor junto do aluno, sendo os direitos de autoria e propriedade do conteúdo sempre do professor, mas disponibilizados à NossoBIM durante um período pré-estabelecido e renovável.

\subsection{Tutoria pedagógica}

Outra peça essencial no apoio aos alunos são os tutores do aluno, mais focados nos aspetos pedagógicos e humanos da relação do aluno com este projeto de aprendizagem. Estes tutores, muitas vezes, têm de atuar como psicólogos ou como amigos, estimulando o aluno a ultrapassar as dificuldades e a saber lidar com as exigências da compatibilização de uma aprendizagem deste tipo, com a sua vida, quer pessoal, quer profissional.

\subsection{Tutoria técnica}

Por fim a tutoria técnica, muitas vezes menos visível, mas essencial para que tudo decorra sem problemas, em vários momentos é chamada a intervir, seja por dificuldades técnicas de instalação de softwares até à gestão de problemas com servidores e plataformas.

\section{Trabalhos individuais e de grupo}

\subsection{Trabalhos individuais}

\section{MÓDULO 2 - INFORMATION MANAGEMENT}

O objetivo da prática é a validação do modelo do edifício 1 , em formato IFC, de um projeto denominado "Tesla". O desenvolvimento do trabalho consiste na deteção, comunicação e resolução de problemas detetados nos modelos BIM das diferentes disciplinas.

\section{MÓDULO 2 - DESENVOLVIMENTO DE OBJETOS}

A prática individual consiste no desenvolvimento de um objeto escolhido pelo aluno dentro do catálogo da "IKEA", em duas plataformas BIM, também eleitas pelo aluno. O objeto desenvolvido deve ser virtualmente o mesmo que o objeto da IKEA escolhido. Para isso deverá, entre outras características, conter informação relevante para a sua utilização (fabricante, modelo, custo, etc.), adaptar-se a distintas variações de catálogo do objeto (geometria, materiais, componentes, etc.) e ser utilizável num projeto real sem necessidade de modificações posteriores. É também imprescindível dotar o objeto definido do maior número possível de funcionalidades parametrizadas.

\section{MÓDULO 4 - BIM IMPLEMENTATION PLAN}

No trabalho prático do Bloco 4, cada aluno deve criar individualmente o seu Plano de Implementação BIM de uma empresa do sector AECO (estúdio/atelier de arquitetura, gabinete/escritório de engenharia, empresa de construção, promotor imobiliário, empresa de gestão, operação ou manutenção de ativos imobiliários, etc.). A empresa em causa, poderá ser real ou fictícia, embora para efeitos deste trabalho prático se considere que a implementação 
BIM será feita numa empresa fictícia e, consequentemente, livre de qualquer questão relacionada com a confidencialidade dos dados apresentados.

\subsection{Trabalhos de grupo}

\section{MÓDULO 1 - BIM SPECIALIST}

A prática consiste no desenvolvimento de trabalho colaborativo para a modelação do Edifício 5 do Projeto Tesla nas 2 plataformas BIM escolhidas pelos alunos (ver Figura 2).
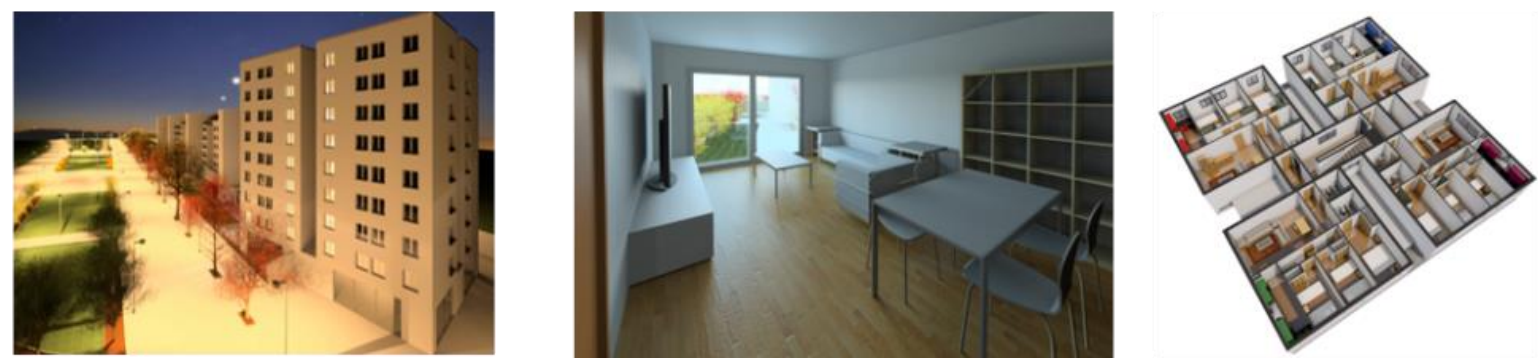

Figura 2: Exemplo de trabalhos de alunos.

\section{MÓDULO 2 - LIVRO DE ESTILO}

O exercício consiste no desenvolvimento do "Livro de Estilo" da organização para o projeto selecionado. Deverão estar perfeitamente definidos os perfis necessários para o desenvolvimento do Projeto Final. O grupo deverá avaliar os perfis BIM de que dispõe.

\section{MÓDULO 3 - BIM EXECUTION PLAN}

Elaboração do BEP - BIM Execution Plan de acordo com os Requisitos do Cliente.

\section{MÓDULO 5 - REABILITAÇÃO SUSTENTÁVEL}

Analisar e estabelecer a solução mais eficiente do ponto de vista ambiental, na redução das emissões associadas em todo o ciclo de vida do edifício - energia e emissões incorporadas na construção, decorrentes da fase de utilização e, se possível, calculadas para a fase de desconstrução/demolição - e também do ponto de vista económico.

\section{MÓDULO 5 - FACILITY MANAGEMENT}

Garantir que os requisitos do cliente cheguem à equipe de manutenção do ativo, nomeadamente, que toda a informação esteja devidamente estruturada e disponível. Além da manutenção, abordar também a gestão do ativo nas suas diversas vertentes (spacing, use, etc.).

\section{MÓDULO 5 - PRODUTOS PARA A INDÚSTRIA}

Cada grupo deverá desenvolver o catálogo da Série Kallax (mínimo 15 produtos). Estes objetos serão empregues para mobilar dois espaços de distintos usos do edifício selecionado.

\section{MÓDULO 5 - INFRAESTRUTURAS}

Aplicar a uma obra de infraestrutura de escolha livre pelo grupo (Rodovia, Ferrovia, Ponte, Túnel, Barragem, etc.), os conceitos de modelação/integração ou de gestão apresentados no Bloco 5 do Master. A partir do exemplo de obra escolhido, não se pretende que o grupo invista muito tempo e recursos no detalhamento, mas antes na aplicação dos conceitos, demonstrando 
pela parte, que seria possível desenvolver o todo de modo exaustivo. A escolha da obra e do trabalho a desenvolver, bem como das ferramentas tecnológicas a utilizar, ficará ao critério livre do grupo, permitindo assim o aproveitamento das sinergias e valências dos elementos do mesmo, bem como do desenvolvimento dos aspetos de maior interesse para cada grupo em particular. Neste sentido, o grupo poderá optar por abordar algum aspeto em qualquer uma das fases do ciclo de vida da obra (projeto, construção, operação). Além disso, poderá optar por uma abordagem mais genérica e global ou antes uma abordagem mais focalizada num aspeto específico ou num detalhe da obra.

\section{Vantagens e desafios}

De um modo global, tem sido percetível ao longo dos anos, que os alunos destacam como grandes vantagens a flexibilidade de gestão de tempo dedicado ao estudo e desenvolvimento de trabalhos práticos, essencialmente pelas características do ensino à distância o qual permite $o$ acesso aos conteúdos, em qualquer lugar e a qualquer hora, bem como o uso de comunicações síncronas e assíncronas que permitem melhorar o fluxo das mesmas. O uso de ferramentas como servidores BIM, armazenamentos na nuvem para partilha de arquivos e informação, bem como de plataformas de gestão e comunicação, são igualmente pontos muito destacados.

Registam-se, no entanto, algumas limitações e dificuldades que estão em permanente análise com vista à sua melhoria. Uma delas prende-se com as características próprias do ensino à distância que, para os alunos com menor disponibilidade de tempo, ou menor dedicação, ou menor disciplina, poderá propiciar a um maior acumular de conteúdos por estudar. Por outro lado, os trabalhos de grupo são por vezes também reveladores da maior inércia deste perfil de aluno, pois habitualmente contribuem menos para o trabalho.

De salientar ainda a iliteracia de alguns alunos no que concerne ao domínio de sistemas operativos e ferramentas digitais. As diversas ferramentas disponibilizadas levam a vários, e por vezes complexos, processos de instalação que, em alguns casos, requerem conhecimentos informáticos, como domínio de antivírus, firewall, gestão de permissões, entre outros, algo que nem todos os alunos dominam.

As duas questões anteriores são as que mais tempo exigem de atenção por parte da direção e da coordenação do curso bem como dos professores, seja na verificação e avaliação minuciosa dos trabalhos para correta e justa classificação de todos os alunos, seja na atenção a fóruns com questões de instalação. As situações acima descritas contribuem também de algum modo para o desânimo de alguns alunos, essencialmente os já identificados como reveladores dessa maior inércia.

Destaca-se ainda situações de perturbações causadas pela dependência de eficazes redes ou ligações, que por vezes levam a elevados períodos para uploads e downloads, sincronizações ou mesmo dificuldades nas comunicações via plataformas de videochamada ou videoconferência.

Por fim, importa referir o processo de negociação com as Software houses, para disponibilização de licenças educacionais, que nem sempre é tão ágil quanto seria desejável, apesar de reconhecerem o interesse geral em colaborarem neste projeto e permitirem aos alunos o teste das suas ferramentas. 


\section{Conclusões}

Com base no apresentado e na avaliação de satisfação dos participantes podemos concluir que o curso tem atingido a qualidade expectável, o que é de realçar face ao ambiente de grande exigência que os profissionais que escolhem este curso imprimem; Testemunhos muito positivos relativos à qualidade do corpo docente, programa e do trabalho colaborativo, são comuns de encontrar nas redes sociais, em voz própria, principalmente na altura em que os alunos concluem o mesmo. O curso tem sido aceite pelos profissionais e escolhido pelas empresas e entidades como a principal oferta formativa de média duração na área da Gestão BIM em Projeto e construção.

Múltiplos têm sido os resultados e frutos destas edições, alguns diretos e outros indiretos, nomeadamente a constituição de várias empresas ligadas ao BIM de entre os alunos e normalmente seguindo os grupos, que por sua vez proliferam as boas práticas e o conhecimento adequado.

A necessidade enorme de aumento da capacitação em BIM dos mercados, em particular dos de língua Portuguesa, tem no International Master BIM Manager uma peça principal, que não só tem contribuído para o aumento de maturidade geral em BIM como também para a criação de uma rede de BIM Managers devidamente formados o que é essencial para a completa disseminação do BIM e como resposta às estratégias e políticas nacionais que se avizinham.

\section{Agradecimentos}

O sucesso que tem sido o International Master BIM Manager só foi possível atingir e manter devido a um conjunto de pessoas e organizações que têm contribuído para tal. Correndo o risco de deixar sempre alguém de fora, os autores agradecem a parceria com a Zigurat desenvolvida durante as primeiras 5 edições do Master, nomeadamente como seu responsável Bernabé Farré, sem a qual provavelmente esta odisseia não se teria concretizado. Igualmente aos colaboradores da Zigurat que trabalharam de modo estreito com a NossoBIM, nomeadamente o Rafael Riera, Jared Gil, Alexandra Ramirez, Barbara Gatti, Ana Santos, Silvia Rojas, Ede Rojas, Alessandro Ferrari, entre muitos outros. Na NossoBIM muitos foram os que nos bastidores permitiram que esta complexa façanha fosse atingida nomeadamente o Daniel Monteiro, Daniel Moutinho, Jesus Vidal, Pablo Ferreiro e Vladimir Domingues. E para último, mas como já realçado no texto um dos fatores de sucesso do nosso curso, o nosso muito obrigado aos professores que nos deram a honra de os representar e a todos que de um ou outro modo colaboraram com o curso emprestando o seu conhecimento e experiência em prol dos alunos, nomeadamente Nuno Lacerda, Décio Ferreiro, Cláudio Lima, Silvio Kimura, Paulo Alves, Eduardo Toledo, Leonardo Manzione, Ivo Mainardi, António Aguiar Costa, Miguel Azenha, Bruno Caires, Francisco Reis, Rogério Susuki, Gustavo Simões, Luísa Madureira, David Oliveira, Filipe Ferreira, Nuno Pires, Pedro Santiago, Rafael Maccheronio, Vanessa Oliveira, Pedro Santos, Tiago Alves, Carlos Paiva, entre outros. Por fim, um agradecimento às Software houses que têm aderido a este projeto através da disponibilização de licenças educacionais que têm permitido aos alunos o uso de diversas ferramentas ao longo do curso. 


\section{Referências}

[1] Maria Bernardete Barison, Eduardo Toledo Santos "BIM Teaching: Current International Trends - Ensino de BIM: tendências atuais no cenário internacional ", 2012

[2] M. Azenha, J.C. Lino, J.P. Couto "Implementação BIM nos projetos de ensino do Departamento de Engenharia Civil da UMinho". $1^{\circ}$ Congresso Português de Building Information Modelling (2016) pp195-205 DOI: https://doi.org/10.5281/zenodo.166758

[3] Arto Kiviniemi, (School of Architecture University of Liverpool) " BIM education - the current and future approach by universities?", in EduBIM2017, Paris, France, 2017.

[4] Abdirad, H., Dossick, C.S. " IM curriculum design in architecture, engineering, and construction education: A systematic review" Journal of Information Technology in Construction, Volume 21, Pages 250-271, 2016

[5] M. Azenha, J.C. Lino, B. Caires, M. Campos, A.A. Costa, N. Lacerda, J.P Martins, F. Reis, J.A. Ribeiro e J.P. Sousa, "Curso BIM: uma abordagem eficiente através de aprendizagem orientada por projetos, dirigida para a indústria da AEC". $2^{\circ}$ Congresso Português de Building Information Modelling (2018) pp195-205 DOI: https://doi.org/10.5281/zenodo.166758, 2018 